\title{
Turning the tide on trash: Empowering European educators and school students to tackle marine litter
}

Bonny L Hartley ${ }^{\mathrm{a}}$, Sabine Pahl ${ }^{\mathrm{a}}$, Matthew Holland ${ }^{\mathrm{a}}$, Iro Alampei ${ }^{\mathrm{b}}$, Joana M Veiga $^{\mathrm{c}}$, and Richard C Thompson ${ }^{\mathrm{d}}$

${ }^{a}$ School of Psychology, Plymouth University, Drake Circus, Plymouth, UK, PL4 8AA

${ }^{b}$ Mediterranean Information Office for Environment, Culture and Sustainable Development (MIO-ECSDE), Athens, Greece

${ }^{c}$ Coastal and Marine Union (EUCC), Netherlands

${ }^{d}$ School of Marine Science and Engineering, Plymouth University, Drake Circus, Plymouth, UK, PL4 8AA

Correspondence concerning this article should be addressed to Bonny Hartley, who is currently at the University of Greenwich, Avery Hill Campus, London, SE9 2UG, UK (B.Hartley@greenwich.ac.uk) or Sabine Pahl (sabine.pahl@plymouth.ac.uk), School of Psychology, Plymouth University, Drake Circus, Plymouth, PL4 8AA, UK.

Funding: This research was supported by funding from the European Union's Seventh Framework Programme for Research and Technological Development and Demonstration [grant agreement no. 289042]. The views and opinions expressed in this publication reflect 
the authors' view and the European Union is not liable for any use that may be made of the information contained therein.

Acknowledgements: The authors are extremely grateful to partners in the MARLISCO project, for their help facilitating the implementation of this research, particularly in translation and data collection across Europe; Province of Teramo (Italy); Coastal \& Marine Union (EUCC) (Netherlands); CEFAS (UK); MerTerre (France); RRC Koper (Slovenia); University College Cork (Ireland); Mare Nostrum (Romania); Kusten Union (Germany); ISOTECH (Cyprus); UBBSLA (Bulgaria); PlasticsEurope (Spain); FFCT UNL (Portugal); MIO-ECDSE (Greece); TUDAV (Turkey); KIMO Denmark (Denmark). 


\section{Highlights}

- This research examined two educational activities for European audiences.

- An online training course for educators and a video competition for students.

- After the activities, understanding and willingness to address the problem increased.

- Educators felt more able and confident to include marine litter in their teaching.

- Students felt more concerned, aware of causes and impacts, and took more action. 


\section{Turning the tide on trash: Empowering European educators and school students to tackle marine litter}

Marine litter is a global environmental problem, and working with educators and school students has much potential to facilitate greater public understanding of the solutions and to enable action. This research examined two new educational activities designed to empower European educators and school students to engage with the topic of marine litter, particularly focusing on behavior and on known determinants of behavior rather than knowledge alone. In Study 1, 120 educators participated in an online training course on marine litter, and completed a pre- and post-course questionnaire to assess change. After participating in the course, educators felt significantly more skillful and confident to incorporate marine litter education into their future teaching. In Study 2, 341 school students (7-18 years old) participated in an educational video competition on marine litter, and completed a pre-post questionnaire to assess change. Following the educational activity, students were more concerned about marine litter, had a better understanding of the issue, causes and impacts, and reported performing more waste-reduction behaviors. This research brings together educational and behavioral literatures and demonstrates how educational activities can be documented and evaluated systematically in the quest of tackling marine litter.

Keywords: Marine litter, Environmental education; Educators; Children; Education for Sustainable Development 


\section{Introduction}

Litter is prevalent in marine and coastal environments globally and is increasingly attracting academic, policy and media attention due to its considerable negative ecological and socioeconomic impacts $[1,2,3]$. Many sectors of society contribute to marine litter, from industry to fishing and tourism, and tackling the problem must involve concerted efforts across nations, disciplines and with all stakeholders. Human behavior is a major factor contributing to marine litter, and behavioral change all along the supply chain has the potential to reduce the problem $[4,5]$. This paper focuses on the role of the education sector as an important agent of social change [6]. It investigates change in perceptions and behavioral indicators (behavioral intentions and self-reported behavior) following two educational activities and seeks to contribute to good educational practice regarding the issue of marine litter. In particular the focus is on known determinants of behavior such as concern, perceived control and confidence, rather than knowledge alone. In the next section, the relevant environmental, psychological and educational literatures are reviewed which provides the conceptual basis of the research. This is followed by the methodology and results for Study 1 and Study 2, and finally a discussion of the findings, contribution and limitations of the work.

\section{Literature Review and Conceptual Basis of the Paper}

Education is essential for the advancement of sustainable development (e.g., United Nations Decade of ESD - UNESCO, 2014 [6]). Indeed, in the last decade, there has been more emphasis towards developing ownership, empowerment and action in learners, in addition to solely increasing knowledge and awareness [7]. This research seeks to understand how teachers and students can be empowered to deal with marine litter (with empowerment indicating feelings of confidence, control, competence and readiness to act), which will 
ultimately encourage more responsible behaviors. In terms of content, such transformative pedagogies involve participatory teaching and learning methods to promote change in behaviors, and life-skills such as critical thinking, imagining future scenarios and collaborative decision-making [8]. These methods are focused on harnessing intrinsic motivation and deep engagement with the issues. However, the need for more research, integration with behavioral science and environmental psychology approaches, monitoring and evaluation to assess the effectiveness of good practice has been identified as a key priority [6].

Environmental psychology provides a rich body of research on individuals' perceptions of different environmental challenges, such as climate change and energy use. Various theories and approaches describe and test a range of determinants of environmentally relevant behavior $[9,10,11,12,13,14]$. Such determinants and factors include knowledge and awareness, concern, personality, perceived control (also often referred to as self-efficacy or feelings of confidence and competence to act), values, attitudes and worldviews, personal responsibility, moral norms and demographic variables (e.g., age, gender, education level) (for a review see [11]). These factors are likely to apply equally in the present context. For example, knowledge of and concern about litter, and perceived competence and confidence, are expected to correlate with both educators' willingness to incorporate marine litter education into their teaching on the one side, and school students' willingness to take action to reduce marine litter on the other side. Indeed, examining these factors among educators and students in this novel context can help identify barriers to, and opportunity for, guiding effective educational policy and practice. 


\subsection{Research on environmental and sustainability education}

Research with educators suggests that they are keen to implement environmental and sustainability education but lack the confidence, skills and understanding to do so, particularly in an already overcrowded curriculum $[15,16,17]$. Therefore, educators may need better training and support, and materials that are ready for implementation in educational practice. Although teacher training on specific topics is available, it is not standard practice to evaluate the effects of such training courses systematically. Some feedback is typically requested after the activity, but this is often focused on what participants have learnt in terms of content (knowledge) and on how satisfied they were (e.g., $[18,19])$, rather than on evaluating the factors reviewed above that are known to predict action (such as awareness, concern, perceived control or responsibility).

Research with school students suggests that young people are aware of environmental problems [20,21], can behave in an ecologically responsible manner [22], and can shape the perceptions and behaviors of others $[23,24]$. Several systematic reviews have been conducted on environmental education programs but none specifically on marine litter (see $[25,26,27])$. Overall, these reviews suggest that participation in environmental education activities can improve children's environmental knowledge and attitudes. However, again the majority of studies focus on assessing a change in knowledge or attitude after the activity, rather than assessing changes in behavioral determinants (as reviewed above) or behavioral indicators (e.g., behavioral intentions, self-reported behavior). Substantial research on human behavior recognizes that knowledge gain is not typically sufficient for (or a direct cause of) behavior change [28, 29, 30]. Therefore, evaluation should include factors beyond knowledge, as reviewed above such as concern, perceived control, responsibility, and self-reported behavior or behavioral intentions, which are known to be linked to actual behavior. 
In summary, it is evident that there is a lack of research into environmental education on marine litter, with little to no assessment of the impact these have on the target audience. To our knowledge, only two published studies have employed an environmental education activity to raise school students' awareness and engagement in actions to help solve the problem. Hidalgo-Ruz and Thiel (2013) [31] used the opportunity of a citizen science project to engage students (aged 8-16 years) with the topic of microplastics in the marine environment. They worked with 983 students in Chile who sampled, sorted and counted small plastic pieces on local beaches, and entered their data into an interactive website. After the activity, students reported that they found the project interesting and fun, and that they would be likely to participate in other environmental activities in the future. Hartley, Thompson, and Pahl (2015) [32] implemented an environmental education activity with 176 British schoolchildren aged 7-18 years and assessed their level of concern, understanding and self-reported behavior regarding marine litter before and after engaging in the activity. After the educational activity, children were significantly more concerned about marine litter, had a better understanding of the causes and negative impacts, and reported improved behavior. However, more work is needed on engaging teachers, and on engagement methods that allow the children more freedom and creativity to explore the topic, such as creating their own materials rather than a predetermined program of education, in line with transformative pedagogy.

\subsection{The present research}

This research set out to (1) develop two educational activities designed to increase understanding and empower educators and school students to engage with the topic of marine litter and take action, and (2) assess the impact of each activity on learners' understanding, perceptions and behavior. Specifically, Study 1 employed and evaluated an online training 
course for educators across Europe in 2015 in terms of the educators' level of understanding, confidence, perceived skills and competence, sense of responsibility and intentions to integrate marine litter education into their teaching, using a before-after design. It was predicted that after the course, educators would feel that they had a greater understanding and knowledge of the topic, feel significantly more competent, skillful and confident to teach about marine litter, and that they would have positive behavioral intentions following the course, for example offering more lessons and activities about the topic, and encouraging other educators.

Study 2 implemented and evaluated an environmental education activity in the form of a video competition with European schoolchildren in 2014 and examined perceptions and behavior regarding marine litter before and after participating in the activity. It was predicted that after participating in the educational activity, students would be significantly more concerned about marine litter, have a better understanding of the causes and negative impacts, and report engaging in more actions to help tackle the problem.

\section{Methodology}

\subsection{Participants \& Recruitment}

In Study 1, a total of 120 educators (99 females, 21 males) aged 19-62 years (Mean age = $35.39, \mathrm{SD}=9.77)$ participated from 18 countries across Europe (Greece, Romania, UK, Ireland, Italy Portugal, Cyprus, Germany, Turkey, Spain, Denmark, France, Netherlands, Bulgaria, Croatia, Malta, Sweden and Switzerland). Participants included 26 individuals working in formal education (e.g., school teachers), 46 in non-formal education (e.g., NGO and museum staff, activists), 29 in both formal and non-formal education, and 19 who specified another field (e.g., university). The online training course was advertised through 
educational networks, in newsletters and social media. Educators registered via an online platform, provided consent to participate in the study, and later received a debrief with more information.

In Study 2, a total of 341 school students (200 girls, 141 boys) aged 7-18 years ( $M_{\text {age }}$ $=13.54, \mathrm{SD}=2.63$ ) participated from 12 countries across Europe (Portugal, France, UK, Netherlands, Cyprus, Germany, Italy, Slovenia, Ireland, Turkey, Romania, and Spain). School students were recruited for the video contest via educational networks, newsletters and social media, and also through directly contacting school boards and teachers. School teachers and other educators facilitated children's participation with support from the MARLISCO project (Marine Litter in European Seas: Social Awareness and CoResponsibility). Schools provided consent to participate in the study, and confidentiality of responses was ensured. ${ }^{1}$

\subsection{Education Materials}

Study 1 Educator resource pack and online training course. These were developed within the MARLISCO project by the Mediterranean Information Office for Environment, Culture and Sustainable Development (MIO-ECSDE) $)^{2}$. The resource pack 'Know, Feel, Act! to Stop Marine Litter: Lesson plans and activities for middle level students' [33] is designed for educators working with young people aged 10-15 years in formal or non-formal educational settings. It contains 17 learning activities that examine the characteristics, sources, effects and possible ways to tackle marine litter, addressing it from an

\footnotetext{
${ }^{1}$ The number of participants in both studies reflects the number of pre-post questionnaires that could be matched. In Study 1, 51 pre-questionnaires could not be matched with a post-questionnaire ( $70 \%$ completion rate). In Study 2, 825 pre-questionnaires could not be matched with a post-questionnaire ( $29 \%$ completion rate). ${ }^{2}$ MIO-ECSDE is an Athens-based Non-Governmental Organization (NGO) with a long standing experience in the design and production of educational material and the implementation of educational programs. Since 2002, MIO-ECSDE has facilitated an initiative on Education for Sustainable Development (ESD) called MEdIES (www.medies.net) that aims to support the Euro-Mediterranean formal and non-formal educational community to integrate in their teaching practices ESD themes and pedagogies.
} 
environmental, societal, cultural and economic point of view. The online course trained educators in using the resource pack in their teaching, and aimed at increasing their skills and sense of confidence to do so, with a strong focus on pedagogy rather than marine litter facts. The course was spread over a two week period with no fixed online meetings, enabling participants to $\log$ in and proceed at any time convenient to them (the total workload was around 16 hours). During the course, effective ways of incorporating the pack were demonstrated, learning activities were simulated in an interactive fashion, and trainers and participants discussed how they could be adjusted to different teaching needs. Trainees were treated as experts and had opportunities to talk about the validity and appropriateness of the activities and potential obstacles to implementing them. In the current study, the educational pack was provided in English but it has now been translated and can be found online in 15 languages (http://www.marlisco.eu/education.en.html).

Study 2 Video Contest. The educational activity was developed within the MARLISCO project by the Coastal and Marine Union (EUCC) ${ }^{3}$ and encouraged school students to think about the sources, impacts and solutions to marine litter. Participating students were asked to prepare a two-minute video on the issue of marine litter, considering some key themes, including: Why is marine litter a concern?; What can be done?; What has been done in our school/local community to deal with it? (see [34]) ${ }^{4}$. This aimed at fostering a sense of citizenship and ownership to give students an active voice in the problem and thus empower them to act. It was designed to be appropriate for learners of different ages,

\footnotetext{
${ }^{3}$ Coastal and Marine Union (EUCC) is a stakeholder and network association with members in 40 countries, founded in 1989 with the aim of promoting a European approach to coastal conservation by bridging the gap between scientists, environmentalists, site managers, planners and policy makers. Since then it has grown into the largest network of coastal and marine practitioners and experts in Europe and neighboring areas.

${ }^{4}$ Once the competition had closed, judging panels were set-up in each country to select the best national video and there was also public voting on the best videos via YouTube.
} 
backgrounds, levels of knowledge and cultures and included hands-on experience and investigative learning.

\subsection{Measures}

Study 1 Questionnaire. Questions were informed by environmental psychology and education literature, forming a quantitative evaluation that participants completed before they began the training course (pre) and again after (post). It took approximately 5 minutes to answer these questions.

The pre-course questionnaire included ten questions designed to assess educators' concern, responsibility, perceived knowledge, perceived understanding, confidence, perceived skills and perceived competence in relation to teaching about marine litter (e.g., ' $I$ feel a responsibility to educate young people about the topic of marine litter'; 'I feel I have the skills to teach about marine litter'; Appendix A). Educators were asked to indicate their (dis)agreement with these statements with response options from 1 to 7 , with end anchor points labeled "strongly disagree" and "strongly agree". The post-course questionnaire included the same questions and an additional set of eight questions designed to assess educators' intentions to integrate marine litter education into their teaching (e.g., 'I plan to develop lessons or activities about marine litter'; 'I will encourage other educators in my network to use the Education Pack on marine litter'; Table 1). Educators indicated their intentions using response options from 1 to 7 , with end anchor points labeled "no, definitely not" and "yes, definitely".

Study 2 Questionnaire. A short online tool was developed, based on Hartley et al. [32], to evaluate the educational activity. Students responded to questions about the problem and whether they were worried about marine litter, the negative impacts and possible causes, the proportion of marine litter that is plastic and its longevity, and they reported their own 
behavior (Appendix B). Students answered all questions (except those about proportion and longevity of plastic) by choosing from four response options (not at all, a little bit, quite a bit, a lot). This smaller range of response options was used so that it was more appropriate for the younger sample. The questionnaire was completed online at school before students began the educational activity (pre) and again afterwards (post). The questionnaire was translated for all participating countries and took approximately 5-10 minutes.

\subsection{Analysis}

Study 1 analysis used paired samples t-tests with Bonferroni correction such that only comparisons with $p<0.005$ are interpreted as significant. Effect size Cohen's $d$ is reported, calculated by taking the difference between the two means and dividing by the pooled standard deviation (i.e., the root mean square of the two SDs). Here, 0.20 is considered a small effect, 0.50 is medium, 0.80 is large, and 1.20 is very large. Study 2 used Wilcoxon's matched-pairs signed ranks test because there was a smaller range of possible response options (not at all, a little bit, quite a bit, a lot). Bonferroni adjustment accounted for multiple comparisons in each response category. Effect size $r$ is reported ( $\mathrm{Z}$ divided by square root of $\mathrm{N}$ ), where 0.1 is considered a small effect, 0.3 is medium and 0.5 is large. Due to unequal sample sizes it was not possible to assess results from different demographic groups (country, age, gender, or educator type) individually or to compare across these groups and maintain reliable or representative findings.

\section{Results}

Study 1 Pre-and post-comparison of perceptions.

After completing the course, educators reported that they knew and understood significantly more about marine litter, $t(119)=11.06, p<0.001, d=1.18$ and $t(119)=9.28, p<0.001, d=$ 
1.05 , respectively. Their confidence and perceived skills increased significantly, $t(119)=$ 9.06, $p<0.001, d=1.13$ and $t(119)=8.17, p<.001, d=0.88$, respectively. Similarly, educators reported greater perceived competence in that they had significantly more ideas for teaching about marine litter, $t(119)=11.36, p<0.001, d=1.37$, and that they could think of more ways to integrate the topic into their teaching, $t(119)=6.66, p<0.001, d=0.83$. Moreover, after participating in the course, educators thought that young people would be more receptive to learning about marine litter, $t(119)=5.60, p<0.001, d=0.63$ (Figure 1).

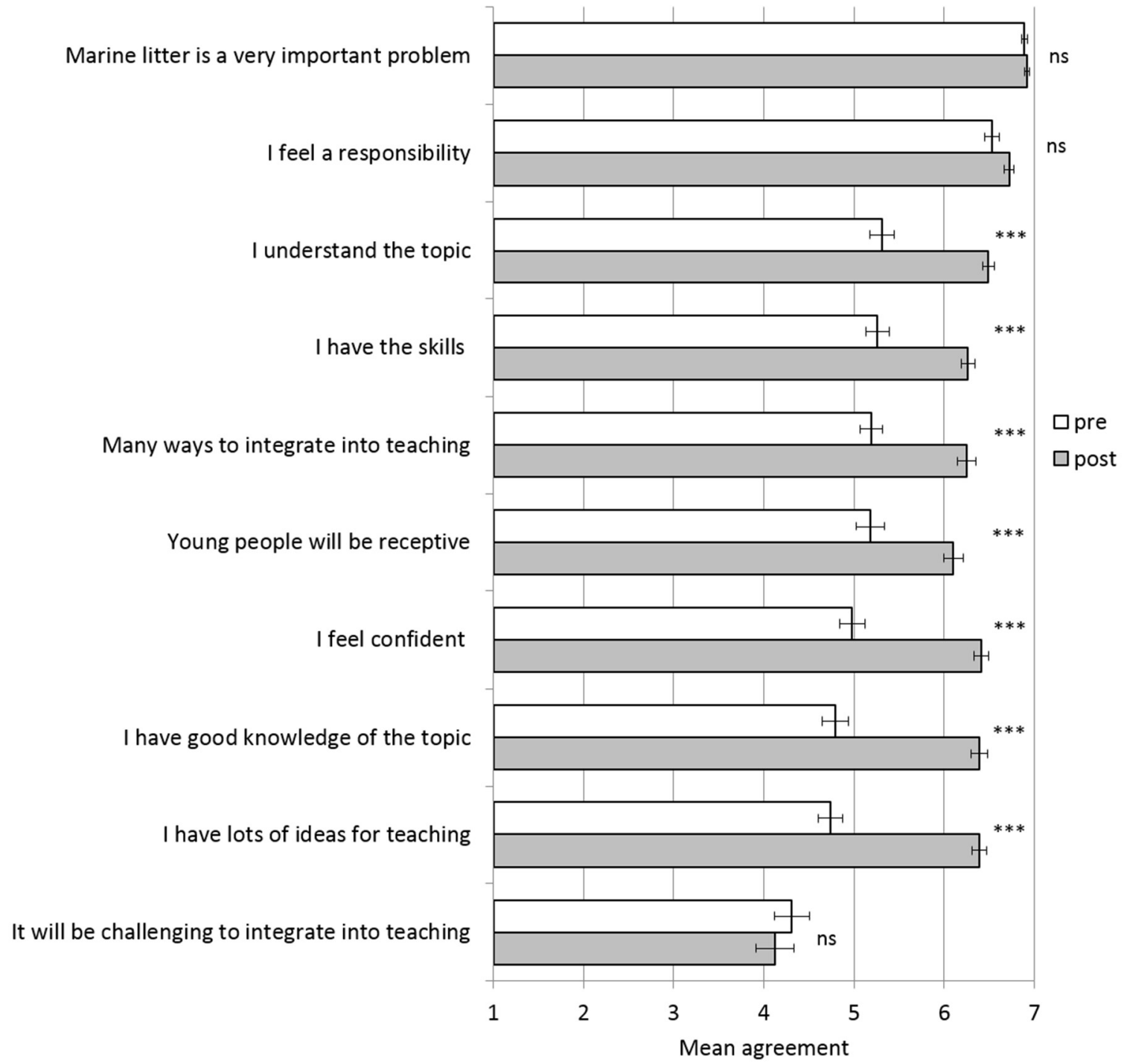

Fig. 1. Educators' pre- and post-course perceptions about marine litter education (1-7:

strongly disagree - strongly agree). Note. Error bars represent standard error. ${ }^{* * *} p<0.001$ 
There was no significant change in perceived importance of the problem, which was already high before the course $t(119)=0.77, p=0.441, d=0.10$, feeling responsible to educate young people about marine litter, $t(119)=2.31, p=0.023, d=0.25$, or perceptions about how challenging it would be to integrate marine litter into teaching (which educators neither agreed nor disagreed with, on average), $t(119)=-1.05, p=0.297, d=0.09$ (Fig. 1).

Study 1 Post-course intentions to integrate marine litter education into teaching After completing the course, educators showed positive behavioral intentions to integrate marine litter education into their future practice (Table 1).

Table 1. Descriptive statistics for educators' intentions to integrate marine litter education into their teaching after completing the online course (1-7: no, definitely not-yes, definitely).

\begin{tabular}{llll} 
& Mean & $S D$ & Median \\
\hline $\begin{array}{l}\text { I am unlikely to have sufficient time to integrate marine } \\
\text { litter education into my teaching }\end{array}$ & 2.17 & 1.45 & 2.0 \\
\hline $\begin{array}{l}\text { I am unlikely to increase the amount of marine litter } \\
\text { education I provide }\end{array}$ & 2.08 & 1.54 & 1.5 \\
\hline $\begin{array}{l}\text { I am unlikely to use the Education Pack 'Know feel act! to } \\
\text { stop marine litter' in my teaching }\end{array}$ & 1.92 & 1.50 & 1.0 \\
\hline $\begin{array}{l}\text { I plan to develop lessons or activities about marine litter } \\
\text { I will tell other educators about marine litter education }\end{array}$ & 6.21 & 1.19 & 7.0 \\
\hline $\begin{array}{l}\text { I will encourage other educators in my network to use the } \\
\text { Education Pack on marine litter }\end{array}$ & 6.42 & 1.02 & 7.0 \\
\hline $\begin{array}{l}\text { I will encourage other educators in my network to } \\
\text { consider including marine litter as a topic in their teaching }\end{array}$ & 6.49 & 1.05 & 7.0 \\
\hline $\begin{array}{l}\text { I intend to integrate marine litter education into my } \\
\text { teaching }\end{array}$ & 6.51 & 0.75 & 7.0 \\
\hline
\end{tabular}


Study 2 Pre- and post-comparisons of perceptions and self-reported behavior Students reported greater worry about the problems that marine litter might cause after participating in the project, $Z=3.61, p<0.001, r=0.20$ (pre- $M=3.38$, post- $M=3.52$ ), but did not change their assessment that marine litter was a very important problem, $Z=1.57, p=$ $0.117, r=0.09$ (pre- $M=3.76$, post $-M=3.80)$. Students increased their estimates on the proportion of plastics in marine litter from $65 \%$ to $73 \%$ on average, $Z=7.57, p<0.001, r=$ 0.41. Their estimates of degradation times also increased from approximately 100 years to 200 years, $Z=4.69, p<0.001, r=0.25$ (note: median scores are reported here because means are skewed by very high values).

Students increased their perceptions of negative impacts for what the beach looks like, human health, and people's enjoyment. Perceptions about impacts on fishermen and on sea animals did not change (Fig. 2 and Appendix C). Students' perceptions about dropping litter on the beach and streets as a cause of marine litter remained unchanged following the video contest. However, students' perceptions about the contribution of all other factors increased significantly (Fig. 3 and Appendix C). After participating in the video contest, students' selfreported waste reduction actions significantly increased (Fig. 4 and Appendix C). No change was reported for throwing litter on the ground, which was already very low. 


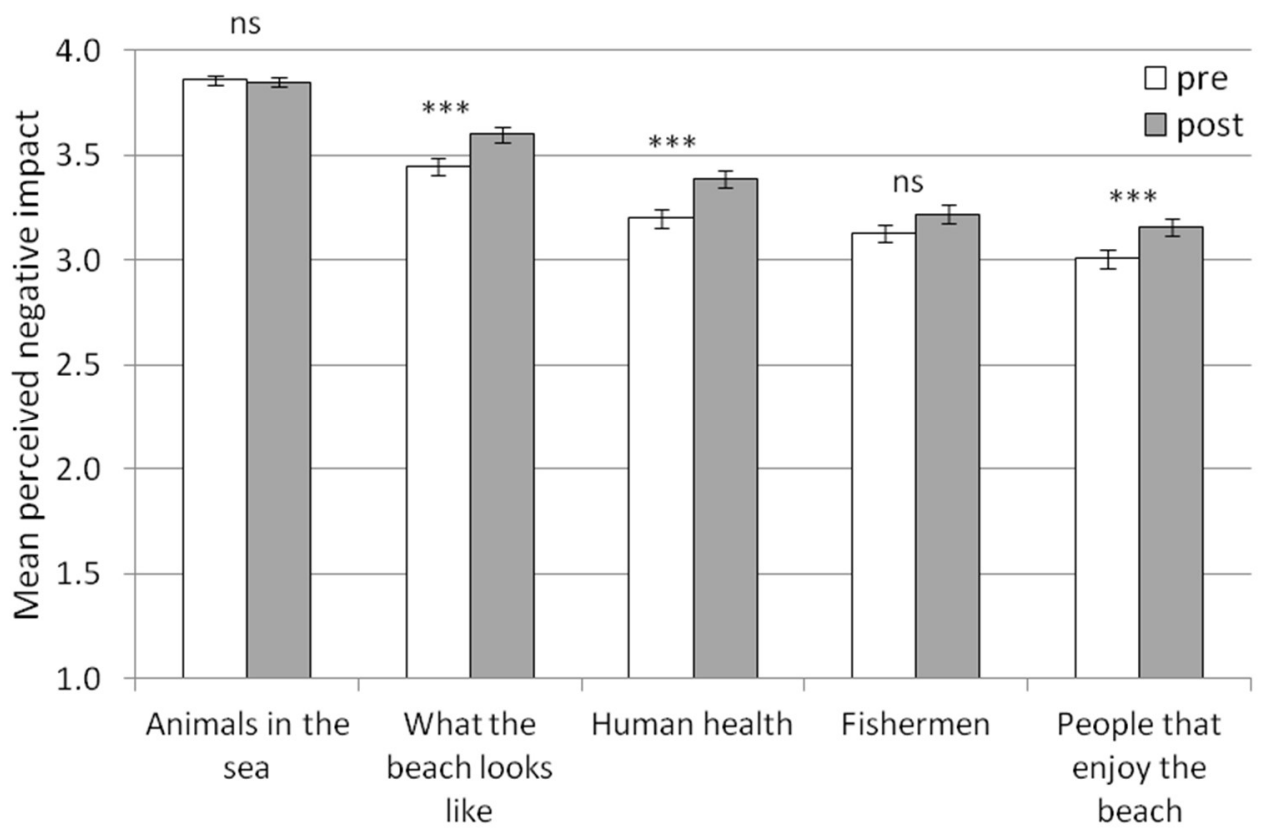

Fig. 2. School students' perceptions about the negative impacts of marine litter pre- and postintervention (1-4: not at all - a lot). Note. Error bars represent standard error. ${ }^{* * *} p<0.001$

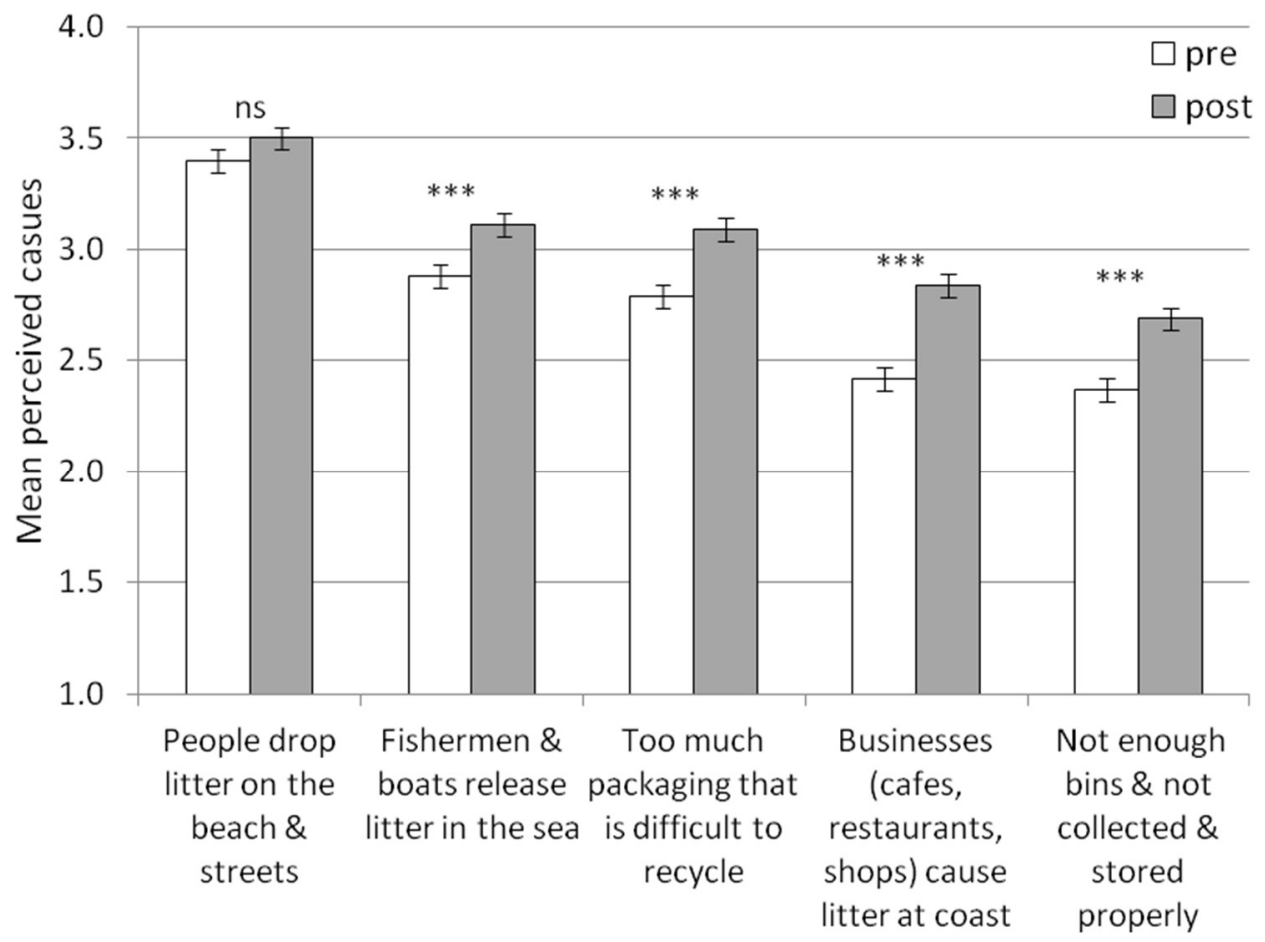

Fig. 3. School students' perceptions about the causes of marine litter pre- and postintervention (1-4: not at all - a lot). Note. Error bars represent standard error. ${ }^{* * *} p<0.001$ 


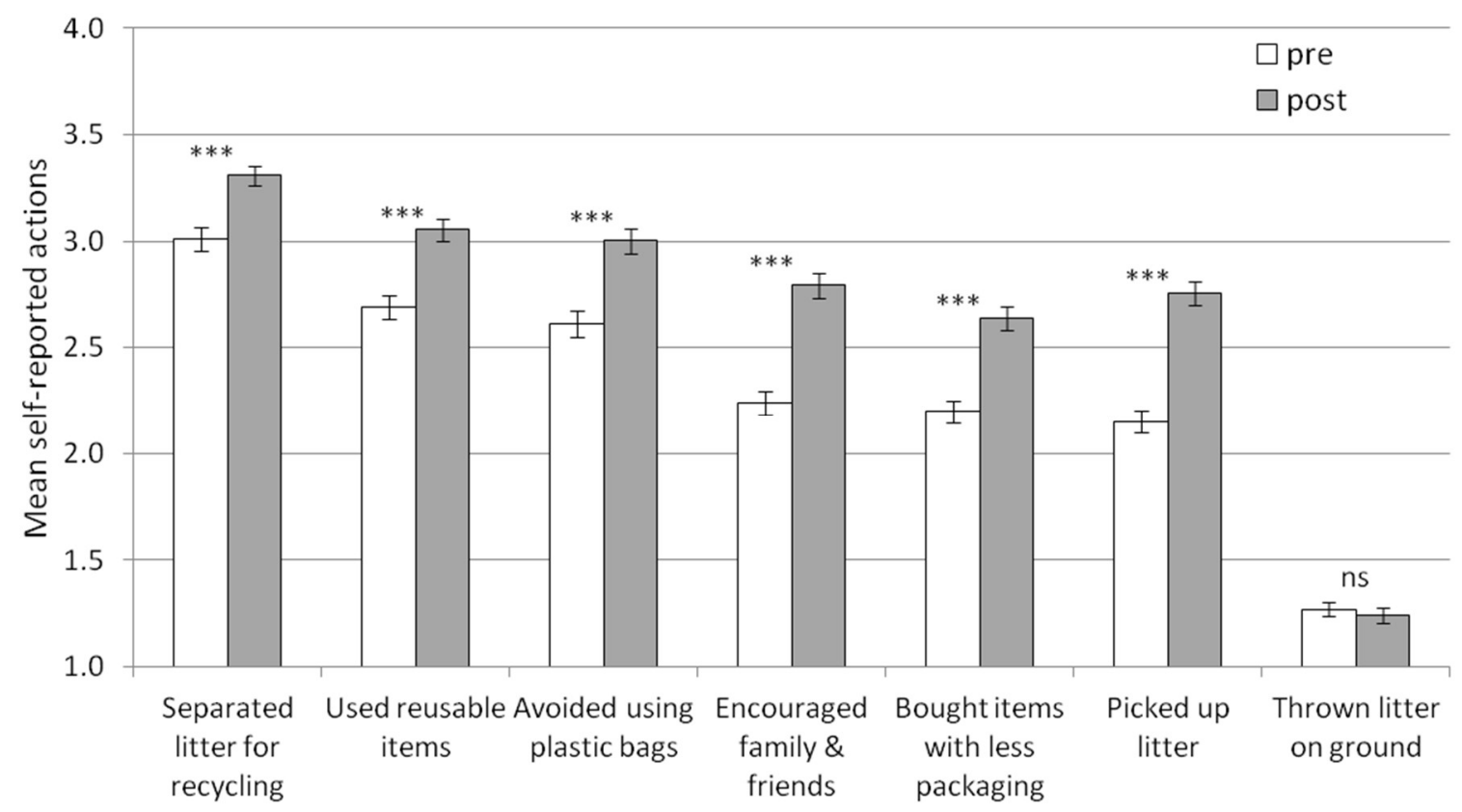

Fig. 4. School students' self-reported actions to reduce the potential causes of marine litter pre- and post-intervention (1-4: not at all - a lot). Note. Error bars represent standard error. $* * * p<0.001$

\section{Discussion}

\subsection{Main findings}

This research tested two educational activities designed to raise understanding and empower both educators (Study 1) and school students (Study 2) to engage with the topic of marine litter and take action. Study 1 showed that participation in an online training course significantly bolstered educators' perceived understanding and knowledge on the topic, and their sense of confidence, competence and skills in marine litter education. Following the training they had high intentions of implementing the materials in their teaching. They also intended to encourage others in their network, which may lead to the training and resources to be distributed more widely. This is promising given previous research showing that educators 
may be keen to implement environmental and sustainability education but lack the confidence, skills and understanding to do so $[15,16,17]$.

Study 2 demonstrated that after participation in an environmental education project in this case a European video competition about marine litter - school students were more concerned about the problem and perceived greater negative impacts and causes. Students also became more accurate at estimating the predominance and longevity of plastic so that their answers came to closely resemble figures commonly reported (cf. reviews $[35,36])$. Moreover, they reported performing more waste reduction behaviors. These findings are novel for the context of marine litter but consistent with previous research that has found positive effects of environmental education activities on understanding, attitudes and behaviors $[25,26,27]$. Students also reported encouraging their family and friends to take action more, which is in line with studies showing that children shape the perceptions and behaviors of others $[23,24]$, indicating the potential of a wider social multiplication effect. Further work is needed to examine this relationship directly.

\subsection{Contribution}

This research represents the first assessment of educators' attitudes and behaviors related to marine litter before and after participation in a training course specifically designed to increase confidence, skills, and willingness to integrate the topic into their teaching practice. It integrates the theoretical insights and methodological approaches from the behavioral sciences into educational programs. Findings contribute to emerging evidence that educators are interested in implementing environmental education, but may benefit from greater confidence and skills to do so $[15,16,17]$. Sustainable development issues, such as marine litter, are complex with interconnected ecological, economic and social dimensions and require expertise in a broad range of knowledge domains as well as problem solving skills 
[37]. The findings support the idea that educators need smart tools that support what they are already doing rather than providing an additional burden. By viewing educators as the experts, the course provided resources, techniques and ideas to facilitate teaching whilst at the same time increasing confidence and perceived skills. This form of training is particularly useful when face-to-face training sessions are not feasible. It allowed educators from across Europe to work together in an online community and share best practices, ideas and experiences - something which would not have been possible with face-to-face national training courses.

In addition, this paper extends Hartley et al.'s 2015 [32] recent study of British students' marine litter attitudes and behaviors and applies similar methods in a Europeanwide environmental education project. Students in the Study 2 reported slightly elevated problem awareness, concern and understanding of the impacts and causes of marine litter compared to the children that Hartley et al. (2015) surveyed [32]. Such differences may be due to a number of factors, such as greater opportunity for self-selection in the current sample (e.g., students volunteering rather than the activity being imposed and led by the teacher), or differences in sample demographics (e.g., students in the current study were on average over 3 years older than in Hartley et al.'s 2015 study). It is encouraging that positive effects are found following both, fairly standardized education activities such as that used in Hartley et al. (2015) and also much freer approaches that rely on self-guided research and learning such as in Study 2 here.

This research represents the first quantitative assessment of European students' attitudes and behaviors related to marine litter before and after participation in an educational project designed to raise awareness and inspire action in the younger generation. A potential extension to this work would be to integrate some open-ended questions which allow school 
students to put forward their own perceptions (or misconceptions) about the causes and negative impacts of marine litter.

\subsection{Implications}

The findings have implications for marine policy by showing how to engage educators and students in the topic of marine litter, in order to raise awareness, confidence and action in learners through environmental education. The education sector represents an important agent of social change in society [6], and it is crucial that educational activities and training are evaluated better, especially taking into account known determinants of behavior in addition to knowledge per se. Several researchers have raised concern that there is a lack of good quality evaluation studies published in the environmental education literature [38, 39, 40, 41]. It is not clear whether this is because the majority of programs do not include evaluation in their projects, or because evaluations that are taking place are not published in the academic literature as perhaps they tend to make less of a contribution to theory $[42,43]$. The evaluations in the current research provided a concise methodology to measure the short term effectiveness of a marine litter educational project and training course, but longer term studies are needed too.

\subsection{Limitations}

First, it is probable that the students and educators that participated in the environmental education project and training course were more conscious of environmental issues, and perhaps marine litter specifically, than the 'average' student or educator. Indeed, educators recruited for the training course were already aware of the problem of marine litter and interested in understanding how to integrate the topic into their teaching; they volunteered to take part. This may limit how generalizable the findings are to less engaged groups, but it is encouraging that each activity had a positive impact even among this interested sample. A 
common challenge is reaching out to educators who are not already aware of or engaged in the topic. Educators have many commitments and are under numerous demands and restrictions within and outside the curriculum. Better incorporation of marine litter in the curriculum and formal teacher training process would give educators greater time, resources, confidence and skills to teach about this and other emerging environmental topics. In addition, greater promotion of and support for schemes through dedicated networks, such as Eco-Schools, would also help establish a norm for schools to consider environmental issues and take action. By engaging educators who are already interested in marine litter and/or who have received resources and undergone training, and by encouraging them to share their experience and skills with fellow educators, there is potential for a snowball or social multiplication effect - educators become the 'trainers', and the network of educators that are reached should continue to grow. Notably, the social psychology literature has shown that even a minority of people can have substantial influence on the majority [44].

Second, there are limitations to the self-report method. Participants may provide responses which are socially desirable, or which they believe are consistent with the goals of the study. Whilst this is a potential limitation, educators and students in this research completed questionnaires online which is likely to suffer less from social desirability than a face-to-face interview methods. In addition, this limitation presents less of a problem for studies which measure changes in responses using a before-after methodology, compared to more basic post-course evaluations where participants reflect on what they have learnt and how satisfied they were with the course.

Third, despite educators being exposed to the same information during the training course, and students participating in the same education project, participants could have sought out or been exposed to more information about marine litter, which was outside of the researcher's control and which could influence their post-intervention questionnaire 
responses. However, any further learning that may have occurred outside the training and education activities could be viewed as an additional outcome. It would be beneficial for future research to include control groups, standardize the length of time between the pre- and post-questionnaire and conduct additional longer term follow-up questionnaires to improve the evaluation methods further.

\section{Conclusion}

Overall, the present research shows how complex environmental issues can be made accessible to educators and school students using online training and creative multimedia methods. Moreover, this work demonstrates not just the feasibility of such methods of engagement but also applied a systematic evaluation method and data. Both educators and school students demonstrated increased understanding and willingness to address the problem of marine litter following the educational activities. 


\section{References}

[1] Gregory, Murray R. 2009. "Environmental Implications of Plastic Debris in Marine Settings-Entanglement, Ingestion, Smothering, Hangers-On, Hitch-Hiking and Alien Invasions." Philosophical Transactions of the Royal Society B: Biological Sciences 364 (1526): 2013-2025. doi:10.1098/rstb.2008.0265.

[2] Gall, Sarah C., and Richard C. Thompson. 2015. "The Impact of Debris on Marine Life." Marine Pollution Bulletin 92 (1-2): 170-179. doi:10.1016/j.marpolbul.2014.12.041.

[3] Mouat, John, Rebeca Lopez Lozano, and Hannah Bateson. 2010. Economic Impacts of Marine Litter. Kommunenes Internasjonale Miljøorganisasjon. https://www.noordzeeloket.nl/images/Economic\%20impacts\%20of\%20marine $\% 201$ itte r_1290.pdf.

[4] Pahl, Sabine, Kayleigh J. Wyles, and Richard C. Thompson. 2017. "Channelling Passion for the Ocean Toward Plastic Pollution". Nature Human Behavior 1: 697-699. doi:10.1038/s41562-017-0204-4.

[5] Pahl, Sabine, and Kayleigh J. Wyles. 2017. "The Human Dimension: How Social and Behavioral Research Methods Can Help Address Microplastics in the Environment." Analytical Methods 9(9): 1404-1411. doi: 10.1039/c6ay02647h.

[6] United Nations Educational, Scientific and Cultural Organization. 2014. Shaping the Future We Want: UN Decade of Education for Sustainable Development. Paris: UNESCO. http://unesdoc.unesco.org/images/0023/002301/230171e.pdf.

[7] Hedefalk, Maria, Jonas Almqvist, and Leif Östman. 2015. "Education for Sustainable Development in Early Childhood Education: A Review of the Research Literature." Environmental Education Research 21 (7): 975-990. doi:10.1080/13504622.2014.971716.

[8] United Nations Educational, Scientific and Cultural Organization. 2012. Shaping the Education of Tomorrow: 2012 Report on the UN Decade of Education for Sustainable Development, Abridged. Paris: UNESCO. http://unesdoc.unesco.org/images/0021/002166/216606e.pdf.

[9] Bamberg, Sebastian, and Guido Möser. 2007. "Twenty years after Hines, Hungerford, and Tomera: A New Meta-Analysis of Psycho-Social Determinants of Pro-Environmental Behavior." Journal of Environmental Psychology 27 (1): 14-25. doi:10.1016/j.jenvp.2006.12.002. 
[10] Gardner, Gerald T., and Paul C. Stern. 1996. Environmental Problems and Human Behavior. Boston, MA: Allyn and Bacon.

[11] Gifford, Robert. 2014. "Environmental Psychology Matters." Annual Review of Psychology 65 (1): 541-579. doi:10.1146/annurev-psych-010213-115048.

[12] Klöckner, Christian A. 2013. "A Comprehensive Model of the Psychology of Environmental Behavior-A Meta-Analysis." Global Environmental Change 23 (5): 1028-1038. doi:10.1016/j.gloenvcha.2013.05.014.

[13] Schultz, P. Wesley. 2001. "The Structure of Environmental Concern: Concern for Self, Other People, and the Biosphere." Journal of environmental psychology 21 (4): 327 339. doi:10.1006/jevp.2001.0227.

[14] Stern, Paul C. 2000. "New Environmental Theories: Toward a Coherent Theory of Environmentally Significant Behavior." Journal of Social Issues 56 (3): 407-424. doi:10.1111/0022-4537.00175.

[15] Cutter-Mackenzie, Amy, and Richard Smith. 2003. "Ecological Literacy: The 'Missing Paradigm' in Environmental Education (Part One)." Environmental Education Research 9 (4): 497-524. doi:10.1080/1350462032000126131.

[16] Evans, Neus, Hilary Whitehouse, and Margaret Gooch. 2012. "Barriers, Successes and Enabling Practices of Education for Sustainability in Far North Queensland Schools: A Case Study." The Journal of Environmental Education 43 (2): 121-138. doi:10.1080/00958964.2011.621995.

[17] Yavetz, Bela, Daphne Goldman, and Sara Pe'er. 2009. "Environmental Literacy of Pre-Service Teachers in Israel: A Comparison between Students at the Onset and End of Their Studies." Environmental Education Research 15 (4): 393-415. doi:10.1080/13504620902928422.

[18] Biasutti, Michele. 2015. "An Intensive Programme on Education for Sustainable Development: The Participants' Experience." Environmental Education Research 21 (5): 734-752. doi:10.1080/13504622.2014.921805.

[19] McConnell, Lindsey C., and Martha C. Monroe. 2012. "Making Online Professional Development Work for Florida Project Learning Tree." Applied Environmental Education \& Communication 11 (3-4): 148-156. doi:10.1080/1533015X.2012.776909.

[20] Cohen, Stewart, and Diane Horm-Wingerd. 1993. "Children and the Environment: Ecological Awareness among Preschool Children." Environment and Behavior 25 (1): 103-120. doi:10.1177/0013916593251005. 
[21] Kahn, Peter H., and Orlando Lourenço. 2002. "Water, Air, Fire, and Earth: A Developmental Study in Portugal of Environmental Moral Reasoning." Environment and Behavior 34 (4): 405-430. doi:10.1177/00116502034004001.

[22] Evans, Gary W., Gernot Brauchle, Aliya Haq, Rachel Stecker, Kimberly Wong, and Elan Shapiro. 2007. "Young Children's Environmental Attitudes and Behaviors." Environment and Behavior 39 (5): 635-658. doi:10.1177/0013916506294252.

[23] Damerell, Peter, Caroline Howe, and Eleanor J. Milner-Gulland. 2013. "ChildOrientated Environmental Education Influences Adult Knowledge and Household Behavior.” Environmental Research Letters 8: 15016-15022. doi:10.1088/17489326/8/1/015016.

[24] Duvall, Jason, and Michaela Zint. 2007. "A Review of Research on the Effectiveness of Environmental Education in Promoting Intergenerational Learning." The Journal of Environmental Education 38 (4): 14-24. doi:10.3200/JOEE.38.4.14-24.

[25] Leeming, Frank C., William O. Dwyer, Bryan E. Porter, and Melissa K. Cobern. 1993. "Outcome Research in Environmental Education: A Critical Review." The Journal of Environmental Education 24 (4): 8-21. doi:10.1080/00958964.1993.9943504.

[26] Rickinson, Mark. 2001. "Learners and Learning in Environmental Education: A Critical Review of the Evidence." Environmental Education Research 7 (3): 207-320. doi:10.1080/13504620120065230.

[27] Stern, Marc J., Robert B. Powell, and Dawn Hill. 2014. "Environmental Education Program Evaluation in the New Millennium: What do We Measure and What Have We Learned?" Environmental Education Research 20 (5): 581-611. doi:10.1080/13504622.2013.838749.

[28] Ajzen, Icek. 2001. "Nature and Operation of Attitudes." Annual Review of Psychology 52 (1): 27-58. doi:10.1146/annurev.psych.52.1.27.

[29] Hines, Jody M., Harold R. Hungerford, and Audrey N. Tomera. 1987. "Analysis and Synthesis of Research on Responsible Environmental Behavior: A Meta-Analysis." The Journal of Environmental Education 18 (2): 1-8. doi:10.1080/00958964.1987.9943482.

[30] Hungerford, Harold R., and Trudi L. Volk. 1990. "Changing Learner Behavior through Environmental Education." The Journal of Environmental Education 21 (3): 8-21. doi:10.1080/00958964.1990.10753743.

[31] Hidalgo-Ruz, Valeria, and Martin Thiel. 2013. "Distribution and Abundance of Small Plastic Debris on Beaches in the SE Pacific (Chile): A Study Supported by a Citizen 
Science Project." Marine Environmental Research 87-88: 12-18.

doi:10.1016/j.marenvres.2013.02.015.

[32] Hartley, Bonny L., Richard C. Thompson, and Sabine Pahl. 2015. "Marine Litter Education Boosts Children's Understanding and Self-Reported Actions." Marine Pollution Bulletin 90 (1-2): 209-217. doi:10.1016/j.marpolbul.2014.10.049.

[33] Alampei, Iro, Vicky Malotidi, Thomais Vlachogianni, and Michael Scoullos. 2014. Know, Feel, Act! to Stop Marine Litter: Lesson Plans and Activities for Middle School Learners. Greece: MIO-ECSDE. http://www.marlisco.eu/education.en.html.

[34] Veiga, Joana M., Thomais Vlachogianni, Sabine Pahl, Richard C. Thompson, Kathrin Kopke, Thomas K. Doyle, Bonny L. Hartley et al. 2016. "Enhancing Public Awareness and Promoting Co-Responsibility for Marine Litter in Europe: The Challenge of MARLISCO." Marine Pollution Bulletin 102 (2): 309-315.

doi:10.1016/j.marpolbul.2016.01.031.

[35] Barnes, David K. A., Francois Galgani, Richard C. Thompson, and Morton Barlaz. 2009. "Accumulation and Fragmentation of Plastic Debris in Global Environments." Philosophical Transactions of the Royal Society B: Biological Sciences 364 (1526): 1985-1998. doi:10.1098/rstb.2008.0205.

[36] UNEP. 2005. Marine Litter: An Analytical Overview. Nairobi: UNEP.

[37] Sleurs, Willy, ed. 2008. Competencies for ESD (Education for Sustainable Development) Teachers: A Framework to Integrate ESD in the Curriculum of Teacher Training Institutes. Comenius 2.1 project 118277-CP-1-2004-BE-Comenius-C2.1. http://www.unece.org/fileadmin/DAM/env/esd/inf.meeting.docs/EGonInd/8mtg/CSCT $\% 20$ Handbook_Extract.pdf.

[38] Carleton-Hug, Annelise, and J. William Hug. 2010. "Challenges and Opportunities for Evaluating Environmental Education Programs." Evaluation and Program Planning 33 (2): 159-164. doi:10.1016/j.evalprogplan.2009.07.005.

[39] Fleming, M. Lynette, and Janice Easton. 2010. "Building Environmental Educators' Evaluation Capacity through Distance Education." Evaluation and Program Planning 33 (2): 172-177. doi:10.1016/j.evalprogplan.2009.07.007.

[40] Rickinson, Mark, Justin Dillon, Kelly Teamey, Marian Morris, Mee Young Choi, Dawn Sanders, and Pauline Benefield. 2004. A Review of Research on Outdoor Learning. London, England: National Foundation for Educational Research and Kings College. 
[41] Zint, Michaela. 2012. "Advancing Environmental Education Program Evaluation: Insights from a Review of Behavioral Outcome Evaluations.” In International Handbook of Research in Environmental Education, edited by Robert Stephenson, Michael J. Brody, Justin Dillon, and Arjen Wals, 298-309. New York, NY: Routledge.

[42] Monroe, Martha C. 2010. "Challenges for Environmental Education Evaluation." Evaluation and Program Planning 33 (2): 194-196. doi:10.1016/j.evalprogplan.2009.07.012.

[43] West, Sarah Elizabeth. 2015. "Evaluation, or Just Data Collection? An Exploration of the Evaluation Practice of Selected UK Environmental Educators." The Journal of Environmental Education 46 (1): 41-55. doi:10.1080/00958964.2014.973351.

[44] Martin, Robin, and Miles Hewstone. 2017. "Minority Influence." In Social Psychology: Revisiting the Classic Studies, edited by Joanne R. Smith and Alexander Haslam, 93107. London: SAGE. 
Appendix A: Study 1 questionnaire items: Educators' pre- and post-course perceptions (1-7: strongly disagree - strongly agree).

\begin{tabular}{|c|c|}
\hline Concept & Item \\
\hline Concern & I think marine litter is a very important problem \\
\hline Responsibility & $\begin{array}{l}\text { I feel a responsibility to educate young people about the topic of marine } \\
\text { litter }\end{array}$ \\
\hline Knowledge & I don't know very much about marine litter \\
\hline Understanding & $\begin{array}{l}\text { I understand the topic of marine litter well enough to include in my } \\
\text { teaching }\end{array}$ \\
\hline Skills & I feel I have the skills to teach about marine litter \\
\hline Confidence & I feel confident to teach about marine litter \\
\hline $\begin{array}{l}\text { Competence in } \\
\text { methods }\end{array}$ & I can think of lots of ways I can integrate marine litter in my teaching \\
\hline $\begin{array}{l}\text { Competence in } \\
\text { creativity }\end{array}$ & I have lots of ideas for teaching about marine litter \\
\hline Ease/difficulty & I think marine litter will be challenging to integrate into my teaching \\
\hline Potential barrier & $\begin{array}{l}\text { I don't think the young people I work with will be very receptive to } \\
\text { learning about marine litter }\end{array}$ \\
\hline
\end{tabular}


Appendix B: Study 2 questionnaire items: School students' pre-post perceptions and behaviors regarding marine litter (1-4: not at all - a lot).

\begin{tabular}{ll} 
Concept & Item \\
\hline $\begin{array}{l}\text { Problem } \\
\text { awareness }\end{array}$ & Do you think litter on the beach and in the sea is a problem? \\
\hline Concern & $\begin{array}{l}\text { Are you worried about the problems that litter on the beach and in the } \\
\text { sea might cause? }\end{array}$ \\
\hline
\end{tabular}

Proportion of What percentage of litter on the beach and in the sea do you think is plastic plastic? (Students provided their answer in an open response box)

Longevity of How long do you think it takes a plastic bottle to breakdown/ plastic decompose? (Students provided a number and circled a unit of time: hours/days/weeks/months/years).

Perceived Do you think litter on the beach and in the sea is bad for...

impacts a) Animals in the sea?

b) People that enjoy the beach?

c) Human Health?

d) Fishermen?

e) What the beach looks like?

Perceived Why is there litter on the beach and in the sea? (How did it get there?):

causes

a) Because people drop litter on the beach and streets

b) Because there are not enough bins and litter is not properly collected and stored

c) Because businesses like cafes, restaurants, and shops cause litter at the coast

d) Because fishermen and boats release litter in the sea

e) Because lots of things we buy have too much packaging that is difficult to recycle'

Self-reported Have you done the following things in the last week?:

waste-reduction a) Picked up litter lying around

behaviors

b) Separated your litter for recycling

c) Bought items with less packaging

d) Avoided using plastic bags in the supermarket

e) Used reusable items, not throw away ones

f) Encouraged family and friends to do all or any of the things above

g) Thrown litter on the ground

Students answered all questions (except those about proportion and longevity of plastic) by choosing from four response options (not at all, a little bit, quite a bit, a lot). 
Appendix C: Children's pre- and post-education attitudes and self-report behaviors about marine litter in Study 2. Means (and standard deviations), number of participants, Wilcoxon $Z$ statistic, $p$ values, and effect size $r$ ( $Z$ divided by square root of $N$ ) are presented comparing preand post-intervention responses.

\begin{tabular}{|c|c|c|c|c|c|c|}
\hline & $\begin{array}{c}M(S D) \\
\text { pre-intervention }\end{array}$ & $\begin{array}{c}M(S D) \\
\text { post-intervention }\end{array}$ & $N$ & $\boldsymbol{Z}$ & $p$ & $r$ \\
\hline Problem awareness & $3.76(0.48)$ & $3.80(0.43)$ & 341 & 1.57 & 0.117 & 0.09 \\
\hline Concern & $3.38(0.72)$ & $3.52(0.65)$ & 341 & 3.61 & $<0.001$ & 0.20 \\
\hline \multicolumn{7}{|l|}{ Impacts: } \\
\hline Animals in the sea & $3.86(0.38)_{\mathrm{a}}$ & $3.85(0.43)_{\mathrm{a}}$ & 341 & 0.34 & 0.736 & 0.02 \\
\hline What the beach looks like & $3.45(0.74)_{b}$ & $3.60(0.64)_{b}$ & 341 & 3.51 & $<0.001$ & 0.19 \\
\hline Human health & $3.20(0.82)_{\mathrm{c}}$ & $3.39(0.76)_{\mathrm{c}}$ & 341 & 3.89 & $<0.001$ & 0.21 \\
\hline Fishermen & $3.13(0.80)_{\mathrm{c}}$ & $3.22(0.85)_{\mathrm{d}}$ & 341 & 1.75 & 0.079 & 0.09 \\
\hline People that enjoy the beach & $3.01(0.82)_{\mathrm{d}}$ & $3.16(0.78)_{\mathrm{d}}$ & 341 & 3.49 & $<0.001$ & 0.19 \\
\hline \multicolumn{7}{|l|}{ Causes: } \\
\hline Dropping litter & $3.40(0.69)_{\mathrm{a}}$ & $3.50(0.64)_{\mathrm{a}}$ & 341 & 2.01 & 0.045 & 0.11 \\
\hline Fishermen and boats & $2.88(0.82)_{b}$ & $3.11(0.80)_{b}$ & 341 & 4.28 & $<0.001$ & 0.23 \\
\hline Too much product packaging & $2.79(0.98)_{b}$ & $3.09(0.96)_{b}$ & 341 & 4.91 & $<0.001$ & 0.27 \\
\hline Coastal businesses & $2.42(0.82)_{\mathrm{c}}$ & $2.84(0.87)_{\mathrm{c}}$ & 341 & 4.90 & $<0.001$ & 0.27 \\
\hline Not enough bins & $2.37(0.91)_{\mathrm{c}}$ & $2.69(0.96)_{\mathrm{d}}$ & 341 & 5.14 & $<0.001$ & 0.28 \\
\hline \multicolumn{7}{|l|}{ Actions } \\
\hline Separated litter for recycling & $3.01(1.03)_{\mathrm{a}}$ & $3.31(0.86)_{\mathrm{a}}$ & 341 & 5.10 & $<0.001$ & 0.28 \\
\hline Used reusable items & $2.69(1.02)_{b}$ & $3.05(0.98)_{b}$ & 341 & 5.45 & $<0.001$ & 0.30 \\
\hline Avoided using plastic bags & $2.61(1.13)_{b}$ & $3.00(1.08)_{b}$ & 341 & 5.13 & $<0.001$ & 0.28 \\
\hline Encouraged family and friends & $2.24(1.02)_{\mathrm{c}}$ & $2.79(1.12)_{\mathrm{c}}$ & 341 & 7.93 & $<0.001$ & 0.43 \\
\hline Bought items with less packaging & $2.20(0.97)_{\mathrm{c}}$ & $2.64(1.03)_{\mathrm{d}}$ & 341 & 6.25 & $<0.001$ & 0.34 \\
\hline Picked up litter & $2.15(0.95)_{\mathrm{c}}$ & $2.75(1.01)_{\mathrm{d}}$ & 341 & 8.68 & $<0.001$ & 0.47 \\
\hline Thrown litter on the ground & $1.27(0.64)_{\mathrm{d}}$ & $1.24(0.66)_{\mathrm{e}}$ & 341 & 0.80 & 0.425 & 0.04 \\
\hline Estimated $\%$ plastic & $65.32(18.44)$ & $73.13(15.27)$ & 341 & 7.57 & $<0.001$ & 0.41 \\
\hline Estimated degradation time (in years) & $15534(121305)$ & $27119(162947)$ & 341 & 4.69 & $<0.001$ & 0.25 \\
\hline
\end{tabular}

Note. Means are based on response options: $1=$ not at all, $2=$ a little bit, $3=$ quite a bit, $4=$ a lot. Subscripts indicate results from Wilcoxon tests for item means that are significantly different at pre-intervention and item means that are significantly different at post-intervention within each category of questions, with significance criteria adjusted for multiple comparisons; impacts $(p<0.01)$, causes $(p<0.01)$, and actions $(p<0.007)$. 